Bangladesh Journal of Neuroscience 2014; Vol. 30 (2): 104-111

\title{
Economic Burden of Head Injury Patients Attending a Tertiary Level Hospital in a Developing Country Like Bangladesh
}

\author{
A.K.M JAKIRUL ALAM ${ }^{1}$, ASIFUR RAHMAN ${ }^{2}$, M MOUDUDUL HAQUE ${ }^{2}$, \\ A.T.M. MOSHAREF HOSSAIN ${ }^{3}$, ZIAUL ISLAM ${ }^{4}$
}

\begin{abstract}
:
Objective: Objective of the study was to estimate the economic burden of head injury (HI) patients attending a tertiary level hospital. This study also tried to determine the socio-demographic characteristics, to estimate direct and indirect cost incurred by the head injury patients and to assess economic burden by different types of accidents causing head injury.Methods:The study was a cross-sectional descriptive study carried out to estimate the economic burden of head injury patients attending a tertiary level hospital during the period from January to June 2010, conducted at the neurosurgery department of Dhaka Medical College Hospital (DMCH). All the conscious head injury patients of both sexes, treated in Neurosurgery department of $\mathrm{DMCH}$, willing to participate in the study were included in the study. Convenience type of non-probability sampling technique was followed and sample size of this study was 110. Face to face interview was conducted with the patient and / or attendant for data collection and specific pre-designed semi-structured and pre-tested questionnaire was used for the interview session. After Categorizing, coding, cleaning and summarizing, all data were analyzed by the software SPSS windows program version 12.0. Result: More than half (53.6\%) of the patients of this study, were in younger age group (21 to 30 years) with mean $( \pm S D)$ age of 29.1 $( \pm 8.36)$ years. Majority of the patients (69.0\%) were males, Average monthly family income of the patients was Tk.14,509.09 ( \pm 5762.49$)$. Majority (36.4\%) of the patients had primary level education while $20.9 \%$ were housewives. Major incidences of different types of accidents included road traffic accident (63.6\%), assault (20.0\%), industrial accident (8.0\%) and fall from height (8.0\%). Average length of the stay of the patients in the hospital was $7.43( \pm 3.64)$ days. In respect of direct cost, average travel cost incurred by the patients was Tk.3,628.18 ( \pm 2055.56$)$, average drug cost was Tk.1,618 ( \pm 801.51$)$, average laboratory investigation cost was Tk.2390 ( \pm 626.47$)$ and average cost of food was Tk.2235.45 ( \pm 1208.19$)$. Average direct treatment cost incurred by the patients was Tk.9590.10 ( \pm 4041.13$)$. The average duration of absent from work place was 7.07 ( \pm 3.316$)$ days and most of the patients average daily income (self) was Tk.340.65 ( \pm 158.97$)$. Average loss of income due to illness was Tk.2415.32( \pm 1623.68$)$ and average cost behind giving tips to hospital staff by the patients was Tk.221.50 ( \pm 78.34$)$. The average indirect cost of these study patients was Tk.2001.72 ( \pm 1869.27$)$. Overall, average treatment cost incurred by the patients was Tk.12,008.05 ( \pm 5051.95$)$. Majority (38.0\%) had a cost from Tk10001 to Tk.15000. Conclusion: The study finding can help policy makers, public health specialists, future researchers and enthusiastic individuals to formulate specific strategies for reduction of economic burden of head injury patients by providing cost-effective health care services throughout the country.
\end{abstract}

Key Word: Head injury (HI), traumatic brain injury (TBI), economic burden,

Introduction:

Head Injury $(\mathrm{HI})$ is a nonspecific and antiquated term, which includes clinically evident external injuries to the face, scalp, and calvarium, such as lacerations, contusions, abrasions, and fractures, and may or may not be associated with Traumatic Brain Injury

1. Medical Officer, Metropolitan Medical Centre, Mohakhali, Dhaka

2. Assistant Professor, Department of Neurosurgery, Bangabandhu Sheikh Mujib Medical University, Shahbag, Dhaka

3. Associate Professor, Department of Neurosurgery, Bangabandhu Sheikh Muja Medical University, Shahbag, Dhaka

4. Associate Professor, Department of Community Medicine National Institute of Preventive and Social Medicine, Mohakhali, Dhaka-1212. 
(TBI). TBI is more properly defined as an alteration in brain function manifest as confusion, altered level of consciousness, seizure, coma, or focal sensory or motor neurologic deficit resulting from blunt or penetrating force to the head ${ }^{1}$. TBI is a critical public health and socio-economic problem throughout the world. It is a major cause of death, especially among young adults, and lifelong disability is common in those who survive ${ }^{2}$.TBI can result in impairments and disabilities, often leading to considerable loss of independence, productivity, and income potential in both industrial-ized and developing countries across the world ${ }^{3,4}$.

The National Center for Injury Prevention and Control estimated that $2 \%$ of US population live with disability as a result of brain injury from traumatic causes alone each year in the USA, 1.7 million people sustains a TBI. 1.4 million of these injured individuals are treated in emergency depart-ments, with around 275,000 hospitaliza-tions and 52,000 fatalities, of which $50 \%$ in hospital, and $50 \%$ out of hospital. A meta-analysis of reports from 23 European countries revealed a hospital admission incidence of 235 per 100,000 people ${ }^{1,2,5}$. By the year 2020, an estimated 10 million people will be affected annually by TBI, and it will surpass many diseases as the major cause of death and disability. This makes TBI a pressing public health and medical problem ${ }^{4}$.The World Health Organization has predicted that road accidents alone, which account for many instances of TBI, will constitute the third largest contributor to the global burden of disease and disability (after heart disease and depression) ${ }^{4}$.

Motor vehicle accidents, falls from height or unintentional falls, fire arm injury, struck by / against a person or object or other types of physical assault, accidents at home, work, outdoors, or while playing sports are among the commonest causes of head injury and $\left.\mathrm{TB}\right|^{3,6}$.

Poverty and morbidity seem to be intertwined with each other. It is a well-recognized fact that, poverty leads to ill-health as poor people are also socially and economically vulnerable due to existing quality of health care along with difficulties in gaining access to and paying for treatment. But much is not known about how morbidity itself can lead to poverty in developing countries. Two things may play role. Firstly, the demise or disability of an income earner in the household reduces future income generation and the resulting depletion of wealth might lead to a lower capacity to invest in the education and wellbeing of the children in the household which again transmits poverty to the next generation. Secondly, when someone falls ill, the household faces several different costs (cost of care giving, transportation, treatment), and to cope with them, it follows diverse strategies. Sometimes the costs are limited, and the household is able to buffer them. Yet, sometimes, the costs are at, or increase to, a level where these coping mechanisms are not sufficient anymore. Some households recover from the financial shock, but others do not and the vicious cycle goes on ${ }^{7,8}$.

In this study we tried to see the economic burden on the persons and their families in our perspective.

\section{Methods:}

The study was a cross-sectional descriptive study carried out to estimate the economic burden of head injury patients attending a tertiary level hospital during the period from January to June 2010. The study was conducted at the neurosurgery department of Dhaka Medical College Hospital. With convenience type of non-probability sampling technique, 110 conscious head injury patients of both sexes admitted in $\mathrm{DMCH}$, meeting the inclusion criteria were enrolled in the study, and unconscious patients and patients with incomplete documentation of investigation data were excluded. Ethical permission for the study was obtained from National Institute of Preventive and Social Medicine (NIPSOM) Ethical Review Committee. Data were collected from the neurosurgery department of $\mathrm{DMCH}$, for duration of 3 weeks from $1^{\text {st }}$ week of May to $3^{\text {rd }}$ week of May, 2010. Data collection was carried out through face to face interview of the patients and / or attendants by asking questions in bangla with specific pre-designed, semi-structured and pre-tested questionnaire. By direct cost it is meant i) hospital cost comprising admission fee and bed charge, ii) consultation fees in private chamber or outdoor, iii) laboratory cost for investigations, iv) drug cost other than supplied free from the hospital, v) attendant cost for the food and others for the attendants and vi) travel cost that 
includes house to hospital and return journey costs of the patient. And the indirect cost includes i) tips / unofficial payment and ii) income loss. After categorizing, coding, cleaning and summarizing, all data were analyzed by the software SPSS windows program version 12.0. Descriptive statistics were done first and then appropriate statistical test were performed to find out the association between different variable as were necessary.

Result:

More than half of the patients $(53.6 \%)$ were in the age group 21 to 30 years and a quarter of the total patients $(25.5 \%)$ were in the age group 31 to 40 years. The average age of the patients was $29.1( \pm 8.36$ ) years. (Table 1 ) Majority of the patients $(69 \%)$ were males and $31 \%$ of the patients were females.

Table-I

Age group of the head injury patients

\begin{tabular}{lcc}
\hline Age group (years) & Frequency & Percentage \\
\hline $10-20$ & 16 & 14.5 \\
$21-30$ & 59 & 53.6 \\
$31-40$ & 28 & 25.5 \\
$41-50$ & 6 & 5.5 \\
$>50$ & 1 & 0.9 \\
\hline Total & 110 & 100.0 \\
\hline
\end{tabular}

40 patients, that is more than one-third ( $36.4 \%)$ of the patients had primary level education followed by $19(17.3 \%)$ illiterate patients, $12(10.9 \%)$ in each were high school and college graduates, 17 (15.5\%) were graduate and $10(9 \%)$ patients completed post graduation. (Table 2).

\section{Table-II}

Educational qualification of the patients

\begin{tabular}{lcc}
\hline Education level & Frequency & Percentage \\
\hline Illiterate & 19 & 17.3 \\
Primary & 40 & 36.4 \\
Secondary & 12 & 10.9 \\
Higher secondary & 12 & 10.9 \\
Graduate & 17 & 15.5 \\
Masters & 10 & 9.0 \\
\hline Total & 110 & 100.0 \\
\hline
\end{tabular}

Out of 34 women, 23 were housewives and rests of both sexes were of different occupations like service $(19,17.3 \%)$, driver $(19,17.3 \%)$, businessman (18, $16.3 \%)$, student $(11,10 \%)$ and of other occupations. (Table 3).

Table-III

Occupation of the patients

\begin{tabular}{lcc}
\hline Occupation & Frequency & Percentage \\
\hline Farmer & 7 & 6.4 \\
Service holder & 19 & 17.3 \\
Business & 18 & 16.3 \\
Teacher & 6 & 5.5 \\
Day labour & 2 & 1.8 \\
Rickshaw puller & 5 & 4.5 \\
Driver & 19 & 17.3 \\
Housewife & 23 & 20.9 \\
Student & 11 & 10.0 \\
\hline Total & 110 & 100.00 \\
\hline
\end{tabular}

Major incidence of different types of accident was road traffic accident $(63.6 \%)$ followed by $20 \%$ assault, $8.2 \%$ industrial accident and $8.2 \%$ fall from height. (Table 4).

Table-IV

Type of accident responsible for head injury

\begin{tabular}{lcc}
\hline Income level (in taka) & Frequency & Percentage \\
\hline Road traffic accident & 70 & 63.6 \\
Assault & 22 & 20.0 \\
Industrial accident & 9 & 8.2 \\
Fall from height & 9 & 8.2 \\
\hline Total & 110 & 100.0 \\
\hline
\end{tabular}

Out of 110 patients, large portion $(47,42.7 \%)$ needed to stay 2 to 5 days in the hospital followed by 38 patients (34.6\%) requiring 6 to 10 days, 24 patients $(21.8 \%)$ requiring 11 to 15 days and only one patient $(.9 \%)$ requiring more than 15 days of hospital stay. (Table 5) 
Table-V

Duration of hospital stay (days)

\begin{tabular}{lcc}
\hline Duration of hospital stay & Frequency & Percentage \\
\hline $2-5$ days & 47 & 42.7 \\
$6-10$ days & 38 & 34.6 \\
$11-15$ days & 24 & 21.8 \\
$16-20$ days & 1 & 0.9 \\
\hline Total & 110 & 100.0 \\
\hline
\end{tabular}

Excluding housewives and students, out of 76 patients who had income, most of the patients' (74, 97.4\%) daily income was below Tk.500. 44 (57.9\%) had daily income of below Tk.300 and 30 (39.5\%) had within Tk.301-Tk.500. Only 2 persons (2.6\%) had daily income income above Tk.500. Average daily income was Tk.340.65( \pm 158.974$)$. (Figure 1)

Seventy six patients were divided into two equal groups of 38 patients each, whose monthly family income was within the range of Tk.5000 to Tk.10000 and Tk.10001 to Tk.15000 respectively. One fifth of the total patients $(20 \%)$ had monthly family income between Tk.15001 to Tk.20000 followed by 10 individuals having income range of Tk.20001 to Tk.25000 and only 2 had a income range of Tk.25001 to Tk.30000. Average monthly income was Tk.14509.09( \pm 5762.494$)$ within a range of Tk.5000 to Tk.30000 per month per family. (Table 6)

Table-VI

Monthly family income of the patients

\begin{tabular}{lcc}
\hline Income level (in taka) & Frequency & Percentage \\
\hline $5000-10000$ & 38 & 34.5 \\
$10001-15000$ & 38 & 34.5 \\
$15001-20000$ & 22 & 20.0 \\
$20001-25000$ & 10 & 9.2 \\
$25001-30000$ & 2 & 1.8 \\
Total & 110 & 100.0 \\
Mean \pm SD & $14509.09 \pm 5762.494$ \\
\hline
\end{tabular}

Travel cost, on an average was Tk. 3628.18 ( \pm 2055.564$)$. The lowest travel cost was Tk. 200 to the highest cost of Tk. 8000. Average cost of drug was Tk.1618 ( \pm 801.516$)$ with minimum Tk. 500 to maximum Tk. 4000 of only one individual. Most of the patients (77.3\%) spent below Tk. 2000 for buying drugs. Average lab investigation cost was Tk. 2390 ( \pm 626.472 ) with a range from Tk. 200 to Tk. 6000. Average cost of food was Tk. $2235.45( \pm 1208.197)$ with a range from Tk. 400 to Tk. 6500 .

Most of the patients' total direct treatment cost was either from Tk. 5001 to Tk. 10000 (40\%) or from Tk.10001 to Tk. 15000 (31.8\%). Some had cost below Tk.5000 (14.5\%) or above Tk.15000 (13.6\%). The average total direct treatment cost incurred by the patients was $9590.10( \pm 4041.138)$. (Table 7).

\section{Table-VII}

Total direct treatment cost

\begin{tabular}{lcc}
\hline Cost (in taka) & Frequency & Percentage \\
\hline $1010-5000$ & 16 & 14.6 \\
$5001-10000$ & 44 & 40.0 \\
$10001-15000$ & 35 & 31.8 \\
$15001-18200$ & 15 & 13.6 \\
\hline
\end{tabular}

Among 76 individuals out of total 110 patients, other than housewives and students who did not have any income generating work, $33(43.4 \%)$ was absent from the workplace for $2-5$ days, $28(36.8 \%)$ for 6 10 days and 15 (19.8\%) for $11-14$ days. (Figure 2)

Average loss of income due to illness was Tk.2415.32 $( \pm 1623.69)$ and minimum Tk.200 to maximum Tk.7000 loss. Average cost behind giving tips to hospital staff by the patients was Tk.221.50( \pm 78.341$)$ and minimum rate was Tk.100 to maximum Tk.500. 4 patients did not give any tips to anybody.

Total average indirect cost was Tk.2001.72 ( \pm 1869.279$)$ ranging from Tk.100 to maximum Tk.8210. (Table 8)

On an average the total cost of the patients was Tk.12008.05 ( \pm 5051.955$)$ with minimum Tk. 3510 to maximum Tk. 23710. More than one-third (38\%) had a cost from Tk.10001 to Tk.15000. (Table 9)

\section{Discussion:}

The aim of the present study was to estimate the economic burden of $\mathrm{HI}$ patients attending in a tertiary care hospital in terms of direct, indirect and total 
costs. We also tried to have evaluation of some demographic characteristics in $\mathrm{HI}$ and TBI.

More than half of the patients (53.6\%) of this study were in the age group 21 to 30 years and a quarter of the total patients $(25.5 \%)$ were in the age group 31 to 40 years. Among the rest, $16(14.5 \%)$ were in the age group 10 to 20 years, $6(5.5 \%)$ were in the age group 41 to 50 years and only one respondent was above 50 years old in our study. In most of the studies the adolescent and the young adults ranging from $15-25$ years, had the highest incidence of TBI which is similar to our study ${ }^{9-11}$.A shift towards older age of patients with TBI has been observed, especially in high-income countries, with falls represent-ing the primary cause of $\mathrm{TBI}$ among the elderly ${ }^{2}$.

Majority of the patients (69\%) were males and 31\% of the patients were females in this study. Like our study, in most of the studies, males were uniformly at higher risk of TBI than were females, with the highest male-to-female (M/F) ratios typically occurring in adolescence and young adulthood. Males are at a higher risk with a male to female ratio ranging from $1.5-4: 1^{12-14}$. Males also tend to have higher rates of TBI-related deaths than females at all age levels ${ }^{3}$.

40 patients that is more than one-third (36.4) of the patients had primary level education followed by 19 $(17.3 \%)$ illiterate patients, $12(10.9 \%)$ each were high school and college graduates, 17 (15.5\%) were graduate and $10(9 \%)$ patients completed post graduation. Schneider et al. ${ }^{15}$ in their study found that, among different groups of patients with different modes of injuries, patients having fewer than 12 years of education had most injuries, followed by patients with 12 to 15 years of education and patients with more than 15 years of education respectively. Majority of patients in the series of Gururaj et al. were with lower levels of education constituting $30 \%$ of the patients. $21.8 \%$ and $11.2 \%$ of patients of that series were illiterate and had only primary education respectively ${ }^{12}$.

Out of 34 women in this study, 23 were housewives and rests of patients of both sexes were of different occupations like service holder $(19,17.3 \%)$, driver $(19,17.3 \%)$, businessman $(18,16.3 \%)$, student (11,
$10 \%)$ with other occupation. One study showed more than a third of the injured persons were involved in semi-professional or skilled occupational categories, $20.5 \%$ and $20.7 \%$ respectively. Housewives and students constituted $6.5 \%$ and $13.7 \%$ respectively in the injured groups in that study ${ }^{12}$.

Commonest cause of injury, we found, was road traffic accidents (RTA) (63.6\%), followed by $20 \%$ assault, $8 \%$ industrial accident and $8 \%$ fall from height. Among the RTA patients, which is the major cause of $\mathrm{HI}$ in our study, 40 (36.4\%) were engaged in driving, one-quarter (25.5\%) were engaged in working as helpers, $15(13.6 \%)$ were pedestrians. In earlier studies, motor vehicle injury used to be the leading cause of TBI, followed by falls, sports and recreation, violence, firearms and others in different percentages ${ }^{16,17}$. But in one more recent study, unintentional falls were the most common cause of TBI ( $37 \%)$, followed by motor vehicle traffic crashes $(26 \%)$, though, among the four major causes, motor vehicle traffic crashes (39\%) led to the highest TBI-related deaths ${ }^{3}$. The scenario is similar as our one in the subcontinent, as in another study in India, among those injured, $59 \%$ of TBIs were due to road traffic injury, followed by falls $(25.0 \%)$ and assaults (10.3\%). Hit by or fall off an external object, work-related injuries and sports injuries accounted for only $2.5 \%, 0.1 \%$, and $0.2 \%$, respectively ${ }^{12}$.

Seventy six patients were divided into two equal groups whose income was either within the range of monthly income of Tk.5000 to Tk.10000 or Tk.10001 to Tk.15000. One fifth of the total patients (20\%) had monthly income between Tk.15001 to Tk.20000 followed by 10 individuals of Tk.20001 to Tk.25000 and only 2 had a income range of Tk.25001 to Tk.30000. Average income was Tk.14509.09 ( \pm 5762.494$)$ within a range of Tk.5000 to Tk.30000. Most of the patients' (97.4\%) daily income was below Tk.500 (57.9\% below Tk.300 and 39.5\% within Tk.301-Tk.500). Only 2 person had daily income above Tk.500. Average daily income was Tk.340.65 ( \pm 158.974$)$. It was interesting to note in an Indian study that, nearly $88 \%$ were with income levels of $<$ Rs. 3000 per month and only $3.7 \%$ had an income of $>$ Rs. 6000 per month ${ }^{12}$. 
Large portion (43\%) needed to stay 2 to 5 days in the hospital followed by $34.5 \%$ needed 6 to 10 days, $22 \%$ needed 11 to 15 days and only one needed more than 15 days. Information on duration of hospital stay was available for 5554 (82\%) of the subjects in a study run by NIMHANS, India. Duration of hospital stay revealed that nearly $45 \%$ of the patients stayed in the hospital for approximately three hours. Among the remaining patients, $26 \%$, $14 \%$ and $3 \%$ stayed for three to six hours, six to 12 hours and 12 to 24 hours, respectively. Nearly 641 $(11 \%)$ patients stayed in the hospital for more than a day. The mean duration of stay for short-term and long-term stay patients was approximately four hours and seven days, respectively. ${ }^{12}$ In the study by McGarry et al. average length of stay in hospital ranged from 6.7 days for moderate TBI to 17.5 days for critical TBI ${ }^{18}$.

Among direct costs of the patients, travel cost was on an average Tk. 3628.18( \pm 2055.564$)$. The lowest cost was Tk. 200 and the highest cost was Tk. 8000. Average cost of drug was Tk.1618 ( \pm 801.516$)$ with minimum Tk. 500 to maximum Tk. 4000 of only one individual. Most of the patients $(77.3 \%)$ spent below Tk. 2000. Average lab investigation cost was Tk. 2390 ( \pm 626.472$)$ ranging from Tk 200 to Tk 6000. Average cost of food was Tk. $2235.45( \pm 1208.197)$ with a range from Tk. 400 to Tk. 6500. In the study at NIMHANS apportioned costs for ambulance services was 34333.00 Rs. and apportioned costs for radiological services was $224415.00 \mathrm{Rs}^{12}$.

Most of the patients' total direct treatment cost was either from Tk. 5001 to Tk. 10000 (40\%) or from Tk.10001 to Tk.15000 (31.8\%). Some had cost below Tk.5000 (14.5\%) or above Tk.15000 (13.6\%). The average total direct treatment cost incurred by the patients was $9590.10( \pm 4041.138)$. At NIMHANS, India, it was seen that the cost of managing one patient per day (in the EMS Department only) is estimated at Rs. 2,152 . This is the lowest possible estimate and in actual values could be much higher. Also, this does not include medical/surgical/ ICU costs of inpatients, which constitute nearly onethird of the head injury patients. Apart from hospital expenses being influenced by severity, duration of stay and intervention procedures, the majority of the families of injured persons had incurred an average expenditure of Rs. 5000/- (sometimes reaching up to Rs.100, 000) during the time of hospital stay. However, this includes only direct medical expenditure and does not include indirect expenses (loss of work, loss of income and others) ${ }^{12}$. Chen et al. showed in their study that emergency department visits were valued at \$187 (CAD, 2007 prices) which was the average (non-weighted) cost of an ED visit and, the estimated average direct medical cost in the first year following an acute care admission for TBI patients was $\$ 32132^{5}$. Runge et al. estimated annual direct cost burden of TBI (mild, moderate, and severe) to be $\$ 302$ million (USD, 2009 prices), whereas Schulman et al. estimated the same direct cost burden as $\$ 98$ million and $\$ 2.8$ billion indirect costs; (USD, 2009 prices) ${ }^{19.20}$.

Among the indirect cost due to injury during the hospital stay, average loss of

income due to illness was Tk.2415.32 ( \pm 1623.69$)$ and minimum Tk.200 to maximum Tk.7000 loss. Average cost behind giving tips to hospital staff by the patients was Tk.221.50 $( \pm 78.341)$ and minimum rate was Tk.100 to maximum Tk.500. In the study at NIMHANS, nearly $50 \%$ each of patients and their family members had lost income during the 1 st year after brain injury. Up to $75 \%$ had incurred heavy expenditure due to injury, even though the exact amount was difficult to quantify and was rated as moderate to severe in nature ${ }^{12}$. The researcher in USA estimated the total productivity loss due to TBI-related deaths at almost $\$ 1.1$ billion annually in Missouri. They also estimated the rate of productivity loss at $\$ 18.8$ million per 100,000 Missouri residents ( $\$ 188$ per person), with a three times higher rate for males ( $\$ 31.7$ million) than for females ( $\$ 6.5$ million $)^{3}$.

Total average indirect cost was Tk.2001.72 $( \pm 1869.279)$ with minimum Tk.100 to maximum Tk.8210. McGregor et al. in their review aimed to evaluate the economic importance and efficiency of rehabilitation programs for TBI patients and found that the costs per case were between $\$ 33,284$ to $\$ 35,954$ for mild and $\$ 25,174$ to $\$ 81,153$ for moderate TBI. These costs are mostly based on acute care ${ }^{21}$. The NIMHANS study showed, among the moderately and severely injured households, 
$50 \%$ and $22 \%$ each had taken substantial loans from outside sources to manage life after injury. Here again, nearly $22 \%$ had experienced serious impact of injury as they experienced severe hardships ${ }^{12}$.

On an average the total cost of the patients was Tk.12008.05 $( \pm 5051.955)$ with minimum Tk.3510 to maximum Tk.23710. More than one-third (38\%) had a cost from Tk.10001 to Tk.15000. Researchers attempted to assess the overall economic impact of brain injury during the first year after injury. While assessing the overall economic impact of brain injury during the first year after injury, the NIMHANS study found that nearly $25 \%$ had incurred expenditure of more than Rs. 100,000/- (US \$1200) with half of them spending more than Rs.25,000/as out-of-pocket expenses for health care alone. Several factors like age, working status, nature of injury, type of care and services utilized along with many other factors determine the total economic impact of brain injuries ${ }^{12}$.

\section{Conclusion:}

Of the head injury and traumatic brain injury patients, road traffic accidents were the most in numbers in our country. Economic burden, especially travel cost, was also found to be higher among these patients. We feel that the government policy makers should make new strategies like extending specialized health care facilities for head injury patients at every peripheral and/or different levels of the country, developing preventive measures to reduce the occurrence of accidents. Strategies like health insurance, subsidized or free of cost treatment can also help in reducing economic burden of the victims. Loss of income was the highest indirect cost incurred by the patients. So, options for prompt and effective clinical interventions should be developed throughout the country to reduce disability and income loss of the head injury patients. All these policies can play a significant role in reducing the bad effects of head injuries and these measures can be implemented at a very low cost in comparison to the total economic burden sustained by the patients and the society.

\section{References:}

1. Bruns J Jr., Hauser WA. The Epidemiology of Traumatic Brain Injury: A Review. Epilepsia, 2003;44:(10):2-10.
2. Roozenbeek B, Maas A I, Menon D K. Changing patterns in the epidemiology of traumatic brain injury. Neurol. 2013;9(4): 231-236.

3. Kayani NA, Homan S, Yun S. Health and Economic Burden of Traumatic Brain Injury: Missouri, Public Health Report 2001-2005. 2009 124(4): 551-60.

4. Humphreys I, Wood R L, Ceri J Phillips C J, Macey $S$. The costs of traumatic brain injury: a literature review. ClinicoEconomics and Outcomes Research 2013;5: 281-87.

5. Chen A, Bushmeneva K, Zagorski B, Angela Colantonio A, Daria Parsons D, Wodchis W $P$. Direct cost associated with acquired brain injury in Ontario. BMC Neurology 2012;12:76

6. Christensen MC, Ridley S, Lecky FE, Munro $\mathrm{V}$, Morris S. Outcomes and costs of blunt trauma in England and Whales. Crit Care 2008; 39(9):1013-25

7. Wagstaff A. Poverty and health sector inequalities. Bulletin of the World Health Organization 2002;80: 97-105

8. Meessen B, Zhenzhoong Z, Damme WV, Devadasan N, Criel B, Bloom G. latrogenic poverty. Trop Med Int Health 2003; 8(7):581-4.

9. Tiret L, Hausherr E, Thicoipe M, et al. The epidemiology of head trauma in Aquitaine (France), 1986: a community-based study of hospital admissions and deaths. Int $\mathrm{J}$ Epidemiol 1990;19(1):133-40

10. Tate RL, McDonald S, Lulham JM. Incidence of hospital-treated traumatic brain injury in an Australian community. AustNZ J Public Health 1998;22(4):419-23.

11. Nell V, Brown DS. Epidemiology of traumatic brain injury in Johannesburg, II: morbidity, mortality and etiology. Soc Sci Med 1991;33(3):289-96.

12. Gururaj G, Kolluri S.V.R, Chandramouli B.A, Subbakrishna D.K and Kraus JF, Traumatic brain injury . National Institute of Mental Health \& Neuro Sciences . 61 ( Bangalore, 560029, India ) ( 2005 ). 
13. Jager TE, Weiss HB, Coben JH, et al. Traumatic brain injuries evaluated in U.S. emergency departments, 1992-1994. Acad Emerg Med 2000;7:134-40

14. Guerrero JL, Thurman DJ, Sniezek JE. Emergency department visits associated with traumatic brain injury: United States, 19951996. Brain Inj 2000;14:181-86.

15. Schneider E B, Sur S, Raymont V, Duckworth J, Kowalski R G, Efron D et al. Functional recovery after moderate/severe traumatic brain injury. A role for cognitive reserve? Neurology 2014;82(18):1636-42.

16. Annegers JF, Grabow JD, Kurland LT, et al. The incidence, causes, and secular trends of head trauma in Olmsted County, Minnesota,1935-1974. Neurology 1980; 30:912-9.
17. Kraus JF, Black MA, Hessol N, et al. The incidence of acute brain injury and serious impairment in a defined population. $A m \mathrm{~J}$ Epidemiol 1984;119(2):186-201.

18. McGarry L J, Thompson D, Millham $F$ $\mathrm{H}$, Cowell L, Snyder P J, Lenderking W $\mathrm{R}$, Weinstein M C. Outcomes and costs of acute treatment of traumatic brain injury. $J$ Trauma. 2002 Dec;53(6):1152-9.

19. Runge JW. The cost of injury. Emerg Med Clin North Am. 1993;11(1): 241-253

20. Schulman J, Sacks J, Provenzano G. State level estimates of the incidence and economic burden of head injuries stemming from nonuniversal use of bicycle helmets. Inj Prev. 2002;8(1):47-52.

21. McGregor K, Pentland B. Head injury rehabilitation in the UK: an economic perspective. Soc Sci Med. 1997;45(2):295-303. 